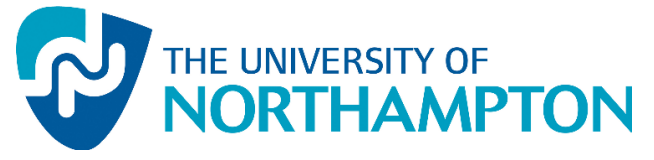

This work has been submitted to NECTAR, the Northampton Electronic Collection of Theses and Research.

\section{Article}

Title: Midwifery preceptorship: the next chapter

Creators: Power, A. and Ewing, K.

DOI: 10.12968/bjom.2016.24.8.582

Example citation: Power, A. and Ewing, K. (2016) Midwifery preceptorship: the next chapter. British Journal of Midwifery. 24(8), pp. 582-584. 0969-4900.

It is advisable to refer to the publisher's version if you intend to cite from this work.

Version: Accepted version

Official URL: http://dx.doi.org/10.12968/bjom.2016.24.8.582

Note: This document is the Accepted Manuscript version of a Published Work that appeared in final form in the British Journal of Midwifery, copyright ( $)$ MA Healthcare, after technical editing by the publisher. To access the final edited and published work see $\mathrm{http}: / / d x$. doi.org/10.12968/bjom.2016.24.8.582.

http://nectar.northampton.ac.uk/8988/

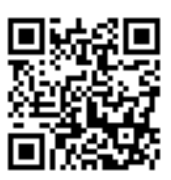


This document is the accepted manuscript version of a published work that appeared in final form in the British Journal of Midwifery, copyright (c) MA Healthcare, after peer review and technical editing by the publisher. To access the final edited and published work see

http://www.magonlinelibrary.com/doi/10.12968/bjom.2016.24.8.582

\title{
Midwifery Preceptorship: the next chapter
}

\begin{abstract}
At the point of registration, the NMC states student midwives should be able to 'practise safely and effectively without the need for direct supervision' (NMC, 2010:23). That said, newly qualified midwives should have a preceptorship period where knowledge and skills are consolidated whilst confidence in practice is developed. This period is not designed to meet shortfalls in pre-registration education; rather it is to support registrants during the transition from student to autonomous and accountable practitioner (Department of Health (DH), 2010a), in other words, the journey from novice to expert (Benner, 2001).

This article will describe preceptorship within the context of midwifery practice and go on to summarise the roles and responsibilities of the 'new registrant', preceptor and employer. It will also discuss a case study preceptorship programme, with narratives from current preceptees and Practice Development Midwife Kate Ewing.
\end{abstract}

Keywords: preceptorship; preceptee; newly qualified; preceptor

\section{Introduction}

Research has found that whilst newly qualified midwives are competent to practise they would benefit from preceptorship programmes providing a structured, supportive culture to enable them to develop their confidence to become autonomous, accountable practitioners (Avis et al., 2013). Furthermore structured preceptorship programmes support newly qualified midwives to enhance their clinical skills, develop their care planning and managerial skills and helps to socialise them into the workplace (Feltham, 2014).

The NMC defines preceptorship as 'providing support and guidance enabling 'new registrants' to make the transition from student to accountable practitioner to:

- practise in accordance with the NMC Code;

- develop confidence in their competence as a nurse, midwife or specialist community public health nurse; 
To facilitate this the 'new registrant' should have:

- learning time protected in their first year of qualified practice;

and

- have access to a preceptor with whom regular meetings are held.

(NMC, 2006:1)

\section{The 'Contract': roles and responsibilities}

Preceptorship is a 'contract' between the 'new registrant' and the preceptor as both parties have responsibilities within their professional relationship. The 'new registrant' must practise according to the Code (NMC, 2015); proactively seek out their preceptor once in post; demonstrate self-awareness by identifying personal learning needs and developing an action plan to address those needs; understand the requirements of their role and their responsibilities to their employer and demonstrate the ability to be a reflective practitioner by seeking feedback from their preceptor and colleagues to inform their future practice.

In turn, the preceptor should support the 'new registrant' in their transition from student to a confident, competent practitioner who provides sensitive, individualised, evidence-based care within the multi-disciplinary team, according to the terms of their contract. The preceptor should give positive feedback on areas of good practice and constructive feedback and support with regards areas for development. The nature of the relationship should be dictated by the 'new registrant's' needs and particular work environment.

\section{Case Study: Milton Keynes University Hospital NHS Foundation Trust}

The NMC recommends a period of preceptorship of not less than 4 months, although it acknowledges that this period of formal support should be tailored to the needs of the individual, availability of preceptor and local circumstances (NMC, 2006). Kate Ewing is a member of the Midwifery Practice Development Team (PDT) at Milton Keynes University Hospital NHS Foundation whose role within the team is to provide back to basic training initiatives, develop the preceptorship programme and oversee mentorship within the unit.

\section{The journey to becoming a Practice Development Midwife (PDM): Kate's Story}

I began my nurse training in 1995 and then went on to specialise in acute medicine and then cardiac care. This was a fast paced exciting environment that I loved; however following my own personal experiences of bereavement I felt the need to change direction, so I started the eighteen-month Midwifery degree in 2000. I worked as a rotational midwife for the next few years but after having children I left midwifery for 5 years, returning in 2010 following a return to 
practice course. Returning after such a long break was a very challenging and stressful experience, but it has given me a great insight into the support needed for staff who are new to practice.

Working clinically, I strived to deliver a high standard of evidence-based care and I found that I particularly enjoyed mentoring students and supporting junior colleagues to develop their skills. When the opportunity arose to join the Practice Development Team (PDT) it seemed a perfect fit - I jumped at it!

\section{What does practice development entail?}

I joined the Practice Development Team 19 months ago and quickly discovered that the role encompassed far more than I had originally anticipated. I was prepared for providing clinical support and developing teaching initiatives to maintain and develop clinical standards throughout the unit, but running a recruitment programme, and line-managing all preceptees were new and unexpected challenges.

My colleagues and I run a successful protected training week every month which all midwives, maternity care assistants (MCAs) and nursery nurses attend annually. This week encompasses both midwifery skills updates as well as mandatory training, including a fun obstetric emergency day which has received great feedback. As a team we also actively promote multidisciplinary training within the unit through PROMPT, weekly CTG meetings and emergency skills drills.

Practice development allows me the opportunity and time to stand back from clinical practice, assess what training would improve clinical standards, liaise with colleagues and area managers, and then research and develop training packages.

\section{My interest in Preceptorship}

My interest in developing and maintaining an effective preceptorship programme for our midwives stems from my own personal experiences. I have experienced 3 preceptorships in my career: firstly as a nurse, then as a midwife and finally as a return to practice midwife, so I am very aware of what is needed to create a supportive environment. I remember very well the fear and uncertainty you experience as you make the transition from student to autonomous practitioner. The following is an extract from my own reflective diary following my first shift as a qualified midwife:

I feel like someone is going to catch me out and tell me to hand back my uniform, I am an imposter midwife who knows nothing! Maybe ' $L$ ' plates should be handed out, so people will give you a break 
Our aim for our preceptees is that they have a clear support network established and developmental goals to work towards, allowing them to create a preceptorship period which meets their individual needs. We are proud as a unit that all staff take the lead in supporting our newly qualified staff. We have a strong team of clinical band $7 \mathrm{~s}$ who provide the first line in clinical support in practice, in addition to our band 6 midwives working alongside preceptees on a daily basis.

As PDMs we provide clinical support in practice which involves visiting clinical areas and offering time to assist with practice questions and support the development of extended skills, for example suturing and cannulation. I feel part of our role is to aid the development of clinical confidence without becoming a mentor taking over the responsibility of care, as this can undermine the preceptee as an autonomous practitioner. In addition, we have established a PDT referral system for staff identified as needing extra support in certain areas in order to gain confidence.

\section{What does preceptorship programme at Milton Keynes include?}

There is general guidance from the $\mathrm{DH}$ on the framework effective preceptorship should take ( $\mathrm{DH}, 2010 \mathrm{a})$; however each trust interprets this guidance to develop its own preceptorship programmes. Locally I have found there to be big differences on what is on offer for newly qualified staff - it is definitely a good question to ask at interview!

I am really proud of the preceptorship programme we have in place and it has received really positive feedback and is proving very attractive to new midwives from other Trusts. Midwives new to the trust receive a structured programme for the first month of practice as a supernumerary member of staff. This month would include:

- 1 week of trust induction

- 1 week protected training

- 2 weeks of clinical rotation to all areas

- 2 days of clinical skill training with the practice development team

Following this month clinical rotation to all areas begins and is allocated for the year ahead. Our preceptorship programme also includes the following:

- 12 month preceptorship programme offering rotation throughout all areas including community

- A preceptorship portfolio intended to be a practical guide to help document and evidence continuing professional development

- Personal PDM allocation - a named support contact to ensure continuity

- 4 monthly practice reviews with a named PDM

- 1 preceptee study day per month, in association with the nursing preceptorship programme

- 2 day IV drug administration training course 
- Day time shift allocation for the first month in a new clinical area

- Weekday PDM support for clinical advice and extended skill development

- Mentorship course allocation following 9 months in practice

- Choice of shift pattern - long or short days

- 2 day infant feeding course

We have had quite a few of our proactive preceptees completing their portfolios to achieve a band 6 within 9 months: the sign of a successful preceptorship programme and hardworking midwives!

\section{How do we plan to develop this further?}

Moving forward we are keen to extend our established support networks by developing a buddy system within the unit. This will involve linking new preceptees with a midwife who has recently completed the preceptorship programme, who will be able to offer support and guidance in completing the portfolio. Currently as PDMs we are fulfilling the role of preceptor which is not ideal; I feel it would benefit our preceptees greatly to have a named clinical link to contribute to this process.

This year we have listened to our preceptees and are restructuring the portfolio to show a clearer progression in the development of practice. We are also liaising closely with the practice development nurses to ensure the shared study days we have introduced have an increased midwifery focus.

Providing a preceptorship programme to suit all is an impossible task as all newly qualified staff are individuals who have qualified with a wide range of clinical experiences. The more individualised we can make preceptorship the better to enable and empower new midwives to make effective use of this exciting time.

\section{Conclusion}

Preceptorship is 'a means of providing structured, focussed support and guidance' (Department of Health (DH), 2010b:36) to newly qualified midwives. There is research and anecdotal evidence to suggest that such support positively impacts on newly qualified midwives' socialisation into their chosen profession and reduces attrition rates. The role of the midwife is emotionally and physically demanding and so initiatives such as preceptorship programmes should be available to all 'new registrants' as they make the transition from novice to expert. 


\title{
References
}

Avis M, Mallik M, Fraser D (2013) 'Practising under your own PIN' - a description of the transition experiences of newly qualified midwives. Journal of Nursing Management 21 1061-1071

Benner P (2001) From Novice to Expert: excellence and power in clinical nursing practice. Upper Saddle River: Prentice Hall

Department of Health (DH) (2010a) Preceptorship Framework for Newly Registered Nurses, Midwives and Allied Health Professionals. Department of Health [online]. Available from:

https://www2.rcn.org.uk/ data/assets/pdf file/0010/307756/Preceptorship fra mework.pdf. [Accessed 18.07.16]

Department of Health (DH) (2010b) Midwifery 2020: Delivering Expectations. London: $\mathrm{DH}$

Feltham C (2014) The value of preceptorship for newly qualified midwives. British Journal of Midwifery 22 (6) 427-43

Nursing and Midwifery Council (NMC) (2015a) The Code: professional standards of practice and behaviour for nurses and midwives. London: NMC

Nursing and Midwifery Council (NMC) (2010) Standards for pre-registration midwifery education. NMC [online]. Available from:

https://www.nmc.org.uk/globalassets/sitedocuments/standards/nmc-standardsfor-preregistration-midwifery-education.pdf. [Accessed 18.07.16]

Nursing and Midwifery Council (NMC) (2006) NMC Circular 21/2006 Preceptorship Guidelines. NMC [online]. Available from:

file:///E:/BJM\%20Articles/Preceptorship/NMC\%202006\%20Preceptorship\%20Gu idelines.pdf. [Accessed 18.07.16]

\author{
Alison Power Senior Lecturer (Midwifery) \\ Kate Ewing Practice Development Midwife \\ Milton Keynes University Hospital NHS Foundation Trust
}

